\title{
Behavioral Profiles of Clinically Referred Children with Intellectual Giftedness
}

\author{
Fabian Guénolé, ${ }^{1}$ Jacqueline Louis, ${ }^{2}$ Christian Creveuil,, ${ }^{3,4}$ Jean-Marc Baleyte, ${ }^{1,4}$ \\ Claire Montlahuc, ${ }^{2}$ Pierre Fourneret, ${ }^{2,5}$ and Olivier Revol ${ }^{2}$ \\ ${ }^{1}$ CHU de Caen, Service de Psychiatrie de l'Enfant et de l'Adolescent, avenue Clemenceau, 14033 Caen Cedex 9, France \\ ${ }^{2}$ Hospices Civils de Lyon, Service Hospitalo-Universitaire de Psychiatrie de l'Enfant et de l'Adolescent, Hôpital Femme-Mère-Enfant, \\ 59 boulevard Pinel, 69500 Bron, France \\ ${ }^{3}$ CHU de Caen, Unité de Biostatistiques et de Recherche Clinique, avenue Clemenceau, 14033 Caen Cedex 9, France \\ ${ }^{4}$ Université de Normandie, Faculté de Médecine, avenue de la Côte de Nacre, 14032 Caen Cedex 5, France \\ ${ }^{5}$ Université Claude Bernard Lyon-1, Faculté de Médecine Lyon Est, 8 avenue Rockefeller, 69373 Lyon Cedex 8, France
}

Correspondence should be addressed to Fabian Guénolé; guenole_fabian@yahoo.fr

Received 21 April 2013; Revised 15 June 2013; Accepted 15 June 2013

Academic Editor: Harold K. Simon

Copyright (C) 2013 Fabian Guénolé et al. This is an open access article distributed under the Creative Commons Attribution License, which permits unrestricted use, distribution, and reproduction in any medium, provided the original work is properly cited.

It is common that intellectually gifted children-that is, children with an IQ $\geq 130$-are referred to paediatric or child neuropsychiatry clinics for socio-emotional problems and/or school underachievement or maladjustment. These clinically-referred children with intellectual giftedness are thought to typically display internalizing problems (i.e., self-focused problems reflecting overcontrol of emotion and behavior), and to be more behaviorally impaired when "highly" gifted (IQ $\geq 145$ ) or displaying developmental asynchrony (i.e., a heterogeneous developmental pattern, reflected in a significant verbal-performance discrepancy on IQ tests). We tested all these assumptions in 143 clinically-referred gifted children aged 8 to 12, using Wechsler's intelligence profile and the Child Behavior Checklist. Compared to a normative sample, gifted children displayed increased behavioral problems in the whole symptomatic range. Internalizing problems did not predominate over externalizing ones (i.e., acted-out problems, reflecting undercontrol of emotion and behavior), revealing a symptomatic nature of behavioral syndromes more severe than expected. "Highly gifted" children did not display more behavioral problems than the "low gifted." Gifted children with a significant verbal-performance discrepancy displayed more externalizing problems and mixed behavioral syndromes than gifted children without such a discrepancy. These results suggest that developmental asynchrony matters when examining emotional and behavioral problems in gifted children.

\section{Introduction}

Although the whole population of intellectually gifted children-that is, children with an intellectual quotient (IQ) higher or equal to 130, according to the main and most consensual definition [1]- seems not to display increased psychiatric morbidity [2], it is highly common that certain of them are referred to paediatric or child neuropsychiatry clinics for socioemotional problems and/or school underachievement or maladjustment [3-6]. Behavioral and emotional problems typically described in intellectually gifted children are anxiety [7], social withdrawal $[8,9]$, low selfesteem [10], and excessive perfectionism [7], which all belong to the category of "internalizing" problems [11]. This common observation of internalizing behavioral problems in gifted children without an increased prevalence of internalizing categorical disorders (i.e., anxiety and mood disorders) in the whole gifted population incites to study its psychopathology dimensionally [12] and also to consider its potential heterogeneity [13].

Indeed, it is long considered that, among gifted children, those with higher IQs display increased adjustment problems [14]. Significant difficulties in social adjustment were common for children with the highest IQs in the famous Terman cohort [15], and Hollingworth reported difficulties increasing with IQ regarding socio-emotional and educational adjustment $[16,17]$. Hollingworth's work suggested that the most desirable intellectual level for gifted children was 
an IQ below 145, a higher one representing a risk factor regarding socio-emotional and educational maladjustment [16]. This was subsequently corroborated by Lewis, who found that gifted children with IQs $\geq 145$ were more maladjusted than the low gifted [18], and Shaywitz and collegues reported increased behavioral problems in highly gifted children compared to the low gifted [13]. A study in clinically referred gifted children points to the same direction, showing socio-emotional problems increasing with IQ [3].

Another notion frequently mentioned when interpreting socio-emotional and educational maladjustment of gifted children is "developmental asynchrony" [19, 20], a term which designates a problematic pattern of heterogeneities between cognitive, emotional, and psychomotor levels, which is seen in the development of gifted children. Psychometrically, developmental asynchrony may be reflected on Wechsler's IQ tests in the verbal-performance discrepancy [21], which quantifies the cognitive imbalance between abilities in verbal abstraction and concrete nonverbal reasoning [22]. Examination of the verbal-performance discrepancy is the hallmark of Wechsler's intelligence profile analysis, with a value $\geq 15$ being considered as significant and indicative of an abnormal profile [22, 23]. A significant verbal-performance discrepancy (SVPD) is seen in approximately one quarter of gifted children [24] - with a verbal prominence in almost all cases-and some data suggest that it is more frequent in gifted children who are clinically referred $[6,25]$. SVPD was found to be associated with social and school maladjustment in gifted children [26], and verbal prominence in clinically referred children with intellectual giftedness was found to be associated with the most serious behavioral symptoms [3].

The purpose of this study was to add to the limited literature related to behavioral profiles of clinically referred children with intellectual giftedness. Our research hypotheses were that (1) they would display increased behavioral problems compared to a normative sample; (2) their behavioral problems would predominate in the internalizing domain; (3) highly gifted children (IQ $\geq 145$ ) would display more behavioral problems than low gifted children $(130 \leq \mathrm{IQ}<145)$; and (4) gifted children with an SVPD would display more behavioral problems than gifted children without an SVPD.

\section{Methods}

2.1. Subjects. The "gifted" group consisted of 144 children, 42 girls (29.2\%) and 102 boys (70.8\%) aged 8 to 11 (mean: $9.3 \pm 1.0$ years) and with a full-scale IQ (FSIQ) higher or equal to 130 on the French version of the Wechsler Intelligence Scale for Children-Third Edition [22]. They were recruited at the department of child and adolescent psychopathology of the "Hospices Civils de Lyon" (France) and through the private practice of four paediatricians in Lyon, where they were referred because of socio-emotional problems and/or school underachievement or maladjustment. Among units, the department of child and adolescent psychopathology of the "Hospices Civils de Lyon" includes a reference center for learning disabilities; the four paediatricians were regular correspondents of the department. All children were examined by trained psychiatrists and psychologists, who performed categorical mental disorder diagnoses according to the fourth version revised of the Diagnostic and Statistical Manual of Mental Disorders [27]. In parallel, a control group matched one-to-one with the "gifted group" for age and gender was recruited in five primary schools randomly chosen among those of the city of Lyon.

Parents of participating children were asked to complete a document comprising the French version of the Child Behavior Checklist (CBCL) and a form for the collection of sociodemographic data. In accordance with the declaration of Helsinki and with the French law, they all signed informed consent after receiving a full description of the study and explanation of its purpose. Results were collected in an anonymous database, according to the requirements of the French national committee for private freedoms.

2.2. The Child Behavior Checklist. The CBCL [28] is a well-established and internationally recognized device for a dimensional assessment of general psychopathology in children and adolescents. It consists of 118 statements about which parents are asked to answer on a 3-point Likert scale how much they apply to their children considering the last 6 months. The CBCL provides a "total score" (TS) for behavioural problems, which can be dichotomized into "internalizing problems" (IP; i.e., self-focused problems, such as feelings of worthlessness or inferiority, dependency, anxiety, excessive sadness, or social withdrawal, which denote overcontrol of behavior and emotion) and "externalizing problems" (EP; i.e., acted-out problems, such as hyperactivity, irritability, rule breaking, or belligerence, which denote undercontrol of behavior and emotion) scores. Based on factor analyses that identified patterns of co occurring items [28], the CBCL also allows individualizing 8 narrow-band dimensional subscores: "withdrawn" (WI), "somatic complaints" (SC), "anxious/depressed" (AD), "social problems" (SP), "thought problems" (TP), "attention problems" (AP), "delinquent behavior" (DB), and "aggressive behavior" (AB).

The French version of the CBCL [29] displays wellvalidated psychometric properties [30], including discriminant validity between referred and nonreferred children [31, 32] and confirmation of the 8-syndrome model [33].

2.3. Data Analysis. Results of one gifted child were removed from analyses because of incorrect filling of the CBCL form; thus, gifted and control groups finally consisted of 143 children.

Sociodemographic (categorical) variables were compared across both groups using chi-square tests; CBCL raw scores and subscores were compared using Student's $t$-tests.

IP and EP standard T-scores (normalized on the distribution in the control group, with 50 indicating average and every 10 points representing one standard deviation) were compared in the gifted group using Student's $t$-test.

CBCL raw scores and subscores were compared within the gifted group between children with FSIQ comprised between +2 and +3 standard deviations above normal average ("low gifted" children: $130 \leq$ FSIQ < 145) and children with 
FSIQ higher than +3 standard deviation above normal average ("highly gifted" children: FSIQ $\geq 145$ ), using Student's $t$-tests. Proportions of children whose scores exceeded cutoff norms for IP (internalizing syndrome), EP (externalizing syndrome), or both (mixed syndrome) were compared across these two groups using chi-square tests or Fisher's exact tests (depending on validity's condition); 90th percentile of scores and subscores distributions in the normative group were used as scale norms, as it is the recommended cut-off for differentiating cases and noncases in French community samples $[30,34]$. The same comparisons were performed between children with and without an SVPD (verbal-performance discrepancy $\geq 15$ ).

CBCL data were computed within the software Assessment Data Manager (ADM) version 7.00 (http://www.aseba.org/); statistical analyses were performed with the software $R$ version 2.15.0 (http://www.r-project.org/); the term "significant" denotes statistical differences at the $P<0.05$ level.

\section{Results}

Sociodemographic characteristics for both groups are listed in Table 1. There was no significant difference for sibling rank, matrimonial situation, and employment of parents. Proportions of parents with high education levels were significantly higher in the gifted group.

Compared mean CBCL scores and subscores are detailed in Table 2. All results were significantly higher in the gifted group.

Mean IQ results in the gifted group were as follow: FSIQ: $138.6 \pm 6.6$ (range: $130-160$ ); verbal scale IQ: $137.3 \pm 7.3$ (range: 121-155), performance scale IQ: $127.6 \pm 9.0$ (range: 108-155). Among the 143 children, 114 (79.7\%) were "low gifted," and 29 (20.3\%) were "highly gifted"; 51 (35.7\%) displayed an SVPD, and 92 (64.3\%) did not. Among the 51 children with an SVPD, verbal scale IQ predominated in 48 cases (94.1\%). No child was diagnosed as suffering from any categorical mental disorder according to DSM-IV-TR.

Mean IP and EP standard T-scores in the gifted group did not significantly differ $(59.8 \pm 13.8$ versus $61.2 \pm 14.6$, resp. $)$.

Mean CBCL raw scores and subscores across "low gifted" children and "highly gifted" children are listed in Table 3. Mean SC subscore was significantly higher in low gifted children $(3.0 \pm 2.8$ versus $1.7 \pm 1.7 ; P<0.05)$; other comparisons showed no significant difference. Proportions of low gifted and highly gifted children with internalizing, externalizing, or mixed syndromes are depicted in Figure 1. Proportion was significantly higher in the highly gifted subgroup for the externalizing syndrome (34.5\% versus $14.0 \% ; P<0.05)$ and in the low gifted subgroup for the mixed syndrome $(24.5 \%$ versus $6.9 \% ; P<0.05)$; there was no significant difference regarding the internalizing syndrome $(16.7 \%$ in the low gifted subgroup versus $10.3 \%$ ).

Mean CBCL raw scores and subscores across gifted children with and without an SVPD are listed in Table 4. Children with a significant SVPD scored significantly higher on the EP score (mean: $18.2 \pm 8.8$ versus $14.8 \pm 9.9 ; P<0.05$ )
TABLE 1: Sociodemographic characteristics of gifted and control groups.

\begin{tabular}{lcc}
\hline & Gifted & Controls \\
& \multicolumn{2}{c}{$n=143$} \\
\hline $\begin{array}{l}\text { Sibling rank } \\
\text { 1st }\end{array}$ & $76(53.1 \%)$ & $67(46.9 \%)$ \\
2nd & $38(26.6 \%)$ & $54(37.8 \%)$ \\
$\quad$ 3rd or more & $29(20.3 \%)$ & $22(15.4 \%)$ \\
Matrimonial situation & & \\
$\quad$ In couple & $136(95.1 \%)$ & $133(93.0 \%)$ \\
$\quad$ Single & $7(4.9 \%)$ & $10(7.0 \%)$ \\
Parent employed & $132(92.3 \%)$ & $137(95.8 \%)$ \\
$\quad$ Father & $97(67.8 \%)$ & $109(76.2 \%)$ \\
$\quad$ Mother & $114(79.7 \%)$ & $81(56.6 \%)$ \\
Parent with high educational level & $82(57.3 \%)$ \\
$\quad$ Father & & \\
$\quad$ Mother & &
\end{tabular}

TABLE 2: Mean CBCL scores and subscores across "gifted" and "control" groups. All comparisons showed significant differences for $P<0.001$

\begin{tabular}{lcc}
\hline & Gifted & Controls \\
& & $n=143$ \\
TS & $44.0 \pm 21.3$ & $24.7 \pm 17.1$ \\
IP & $16.0 \pm 8.8$ & $9.2 \pm 7.2$ \\
EP & $16.0 \pm 9.6$ & $8.6 \pm 6.9$ \\
WI & $4.2 \pm 2.7$ & $2.7 \pm 2.3$ \\
SC & $2.8 \pm 2.7$ & $1.5 \pm 2.1$ \\
AD & $9.0 \pm 5.7$ & $5.0 \pm 4.5$ \\
SP & $3.9 \pm 3.0$ & $2.1 \pm 2.4$ \\
TP & $1.5 \pm 1.9$ & $0.5 \pm 0.9$ \\
AP & $6.6 \pm 4.1$ & $4.3 \pm 3.6$ \\
DB & $3.4 \pm 2.4$ & $1.7 \pm 1.6$ \\
AB & $12.5 \pm 7.4$ & $5.9 \pm 6.9$ \\
\hline
\end{tabular}

TS: total score; IP: internalized problems; EP: externalized problems; WI: withdrawn; SC: somatic complaints; AD: anxious/depressed; SP: social problems; TP: thought problems; AP: attention problems; DB: delinquent behaviour; $\mathrm{AB}$ : aggressive behaviour.

and on the $\mathrm{AB}$ subscore $(14.3 \pm 6.5$ versus $11.5 \pm 7.7$; $P<0.05)$. Proportions of gifted children with and without an SVPD who displayed internalizing, externalizing, or mixed syndromes are depicted in Figure 2. Proportion was significantly higher in the SVPD subgroup for the mixed syndrome (33.3\% versus $19.1 \% ; P<0.01)$; other comparisons showed no significant difference (internalizing syndrome: $11.8 \%$ in the SVPD subgroup versus $17.4 \%$; externalizing syndrome: $19.6 \%$ versus $17.4 \%$ ).

\section{Discussion}

Our results show that clinically referred gifted children display significant and varied behavioral problems, which 
TABLE 3: Mean CBCL raw scores and subscores across "low gifted" children and "highly gifted" children.

\begin{tabular}{lcc}
\hline & Low gifted & Highly gifted \\
$n=114$ & $n=29$ \\
\hline TS & $44.8 \pm 21.6$ & $41.1 \pm 20.4$ \\
IP & $16.7 \pm 8.9$ & $13.3 \pm 7.6$ \\
EP & $16.0 \pm 9.9$ & $16.1 \pm 8.4$ \\
WI & $4.4 \pm 2.7$ & $3.8 \pm 2.9$ \\
SC & $3.0 \pm 2.8$ & $1.7 \pm 1.7$ \\
AD & $9.3 \pm 5.8$ & $7.8 \pm 5.3$ \\
SP & $3.9 \pm 2.9$ & $4.1 \pm 3.3$ \\
TP & $1.6 \pm 1.9$ & $1.3 \pm 1.8$ \\
AP & $6.7 \pm 4.2$ & $6.2 \pm 4.0$ \\
DB & $3.5 \pm 2.5$ & $3.2 \pm 2.2$ \\
AB & $12.4 \pm 7.5$ & $12.9 \pm 6.8$ \\
\hline
\end{tabular}

${ }^{*} P<0.05$.

TS: total score; IP: internalized problems; EP: externalized problems; WI: withdrawn; SC: somatic complaints; $\mathrm{AD}$ : anxious/depressed; SP: social problems; TP: thought problems; AP: attention problems; DB: delinquent behaviour; $\mathrm{AB}$ : aggressive behaviour.

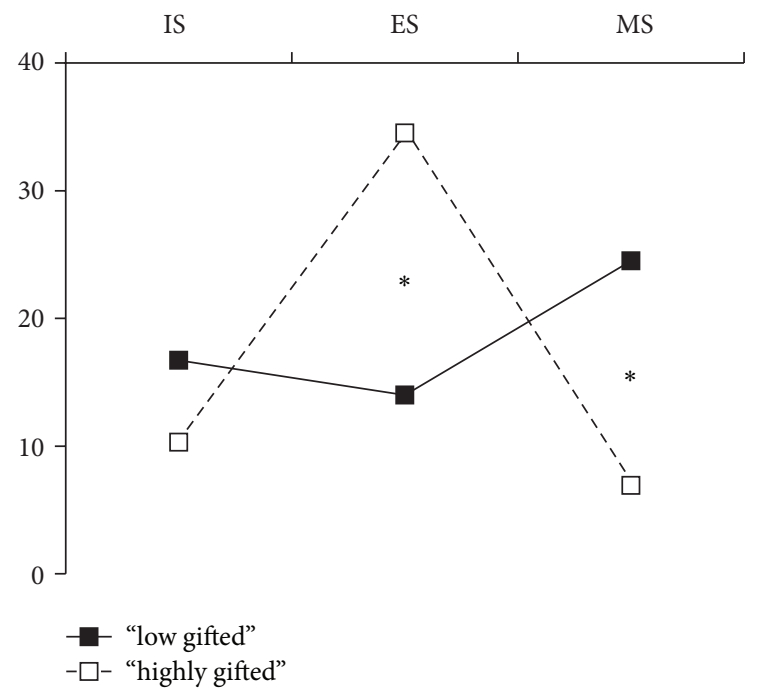

Figure 1: Proportions (\%) of "low gifted" $(n=114)$ and "highly gifted" ( $n=29$ ) children whose scores exceeded norms on "Internalized problems," "externalized problems," or both. ${ }^{*} P<0.05$. IS: internalized syndrome; ES: externalized syndrome; MS: mixed syndrome.

confirms our first hypothesis. Taking main French CBCL surveys as references [31,32], results observed in our gifted group are situated between those obtained in the general population and those obtained in psychiatric outpatient clinics, but closer to the latter. This indicates that clinically referred gifted children represent overall a behaviorally pathological group, of rather moderate symptomatic intensity.

This conclusion could appear contradictory with the fact that no gifted child had a mental disorder according to DSM-IV-TR. However, It must be stressed in this respect that the CBCL model, which provides an empirically based
TABLE 4: Mean CBCL raw scores and subscores across gifted children with and without a significant verbal-performance discrepancy (SVPD).

\begin{tabular}{lcc}
\hline & SVPD & No SVPD \\
& $n=51$ & $n=92$ \\
\hline TS & $48.4 \pm 20.0$ & $41.6 \pm 21.8$ \\
IP & $17.7 \pm 9.5$ & $15.0 \pm 8.2$ \\
$\mathrm{EP}^{*}$ & $18.2 \pm 8.8$ & $14.8 \pm 9.9$ \\
$\mathrm{WI}$ & $4.5 \pm 2.8$ & $4.1 \pm 2.7$ \\
$\mathrm{SC}$ & $3.2 \pm 3.5$ & $2.5 \pm 2.1$ \\
$\mathrm{AD}$ & $10.0 \pm 5.8$ & $8.4 \pm 5.6$ \\
$\mathrm{SP}$ & $4.2 \pm 2.8$ & $3.8 \pm 3.0$ \\
$\mathrm{TP}$ & $1.5 \pm 1.8$ & $1.6 \pm 1.9$ \\
$\mathrm{AP}$ & $7.1 \pm 3.9$ & $6.4 \pm 4.3$ \\
$\mathrm{DB}$ & $3.7 \pm 2.5$ & $3.3 \pm 2.4$ \\
$\mathrm{AB}$ & $14.3 \pm 6.5$ & $11.5 \pm 7.7$ \\
\hline
\end{tabular}

${ }^{*} P<0.05$.

TS: total score; IP: internalized problems; EP: externalized problems; WI: withdrawn; SC: somatic complaints; $\mathrm{AD}$ : anxious/depressed; SP: social problems; TP: thought problems; AP: attention problems; DB: delinquent behaviour; $\mathrm{AB}$ : aggressive behaviour.

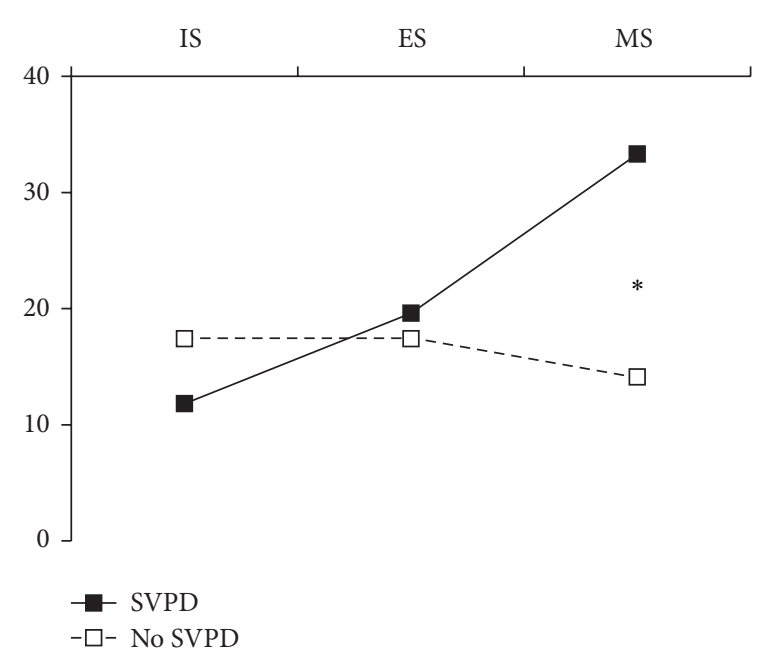

FIgURE 2: Proportions (\%) of gifted children with $(n=51)$ and without $(n=92)$ a significant verbal-performance discrepancy (SVPD) whose scores exceeded norms on "internalized problems," "externalized problems," or both. ${ }^{*} P<0.01$. IS: internalized syndrome; ES: externalized syndrome; MS: mixed syndrome.

dimensional approach of childhood behavioral, emotional, and social problems, has been devised precisely as a complement to categorical nosology in child and adolescent psychiatry [35] in order to compensate some of its intrinsic limits $[12,36]$. Indeed, it is well established that a significant number of clinically referred children with behavioral problems do not enter any diagnostic category in DSMIV-TR [36, 37], whereas a significant proportion of them display discriminating CBCL profiles [12,35]. Incidentally, this led international experts to consider introducing new diagnostic categories when designing the recently published 
fifth version of the Diagnostic and Statistical Manual of Mental Disorders-for example, the very debated "severe mood dysregulation disorder" or "disruptive mood dysregulation disorder" categories [38] — which justifications were to reflect the conditions of these "nosologic orphans" [39]. Most of the gifted children in this study, who displayed distributed behavioural profiles, could belong to this still imprecise but symptomatically significant categories.

This is consistent with the result that, contrary to the second hypothesis, internalizing behavioral problems did not predominate over externalizing ones in the gifted children. This illustrates the dispersion of individual behavioral profiles and the fact that many children displayed predominantly externalizing behavioral problems or a mixed pattern of both internalizing and externalizing problems. Epidemiological literature showed a gradient of severity in the symptomatic nature of behavioral syndromes, internalizing syndromes being associated with better clinical outcomes than externalizing syndromes $[40,41]$ and both with better outcomes than mixed syndromes $[41,42]$. Thus, even if our clinically referred gifted children group globally displayed behavioural problems in the low symptomatic range, the symptomatic nature of behavioral syndromes was more severe than expected.

We found that very high IQs among the gifted were not at all associated with increased behavioral problems, which does not support the third hypothesis. On the contrary, it was low gifted children who displayed more somatic complaints. Also, children with very high IQs displayed less mixed syndromes than low gifted. All these findings do not corroborate the usual claim that children with higher IQs among gifted are more behaviorally impaired than others. In contrast, and supporting our fourth hypothesis, gifted children with an SVPD exhibited psychopathology of relatively severe nature implying emotional and behavioral dysregulation.

In the field of psychopathology, SVPD is a classical feature of Asperger syndrome [43], a mild form of pervasive developmental disorder (PDD) with which behaviourally impaired children with intellectual giftedness often share characteristics [44]: verbal precocity, hyperlexia, hypercalculia, semantic hypermnesia, absorbing interests in specialized topics (with limited social sharing), social withdrawal, anxiety, excessive perfectionism, perceptive hypersensitivity, and motor clumsiness. Intellectual giftedness is common in mild forms of PDDs [45, 46], where this cooccurrence has been conceptualized as one of "twice-exceptionalities" [46]. These children with PDDs and intellectual giftedness exhibit both internalizing and externalizing behavioral problems [46]. As PDDs are thought to represent the high-level cooccurrence of continuously distributed quantitative traits [47], it could be hypothesized that a significant proportion of clinically referred gifted children may be situated at the border of such developmental atypicalities. Incidentally, it has been observed that gifted children with behavioral impairment tend to minimize their problems $[48,49]$, which could reflect defective coping implying denial [50] and thus corroborate the hypothesis that they globally display psychopathological features of rather severe symptomatic nature.

Several limitations must be acknowledged when interpreting results of this study. The first one is the definition of giftedness on the single basis of high IQ. Indeed, giftedness has been conceptualized as additionally entailing increased creativity [51], and it is possible that not all children in this study would have remained labeled as gifted using such a restrictive definition. However, the definition which was used here was the minimal and most consensual one [1]. Secondly, while the gifted and normative groups were matched for sex, thus allowing a control for boys' overrepresentation in the former-which is also found in the general population of gifted [52] - when comparing both, we did not control the effect of parental high academic levels-which is another long known feature of gifted children [15] — on behavioral profiles. However, since our first hypothesis was only descriptive, statistical control of socioeconomic variables was unneeded; incidentally, considering that high academic levels of parents are associated with lower child behavioral problems [53], such a statistical control would probably have amplified contrasts between the two groups. A third limitation is the absence in the gifted group of children with an FSIQ higher than 160, which restricts our testing of the third hypothesis. Actually, such children are very few (approximately 1/10000 in the general population; [1]), but their total absence in our clinical cohort suggests that they are not the most behaviorally impaired across the gifted IQ range. Finally, whereas SVPD is a well-established indicator of cognitive imbalance [54], it would be useful in future research to characterize developmental asynchrony more precisely, for example, with Piagetian concrete and formal operational tasks [55], whose combination with IQ tests allows a deeper description of reasoning heterogeneity [56].

To conclude, results of this study suggest that developmental asynchrony matters when considering psychopathology in gifted children. Further research would be needed in order to clarify the psychopathological vulnerabilities of gifted children and their clinical expressions.

\section{Abbreviations}

$\begin{array}{ll}\text { AB: } & \text { Aggressive behavior } \\ \text { AD: } & \text { Anxious/depressed } \\ \text { AP: } & \text { Attention problems } \\ \text { CBCL: } & \text { Child Behavior Checklist } \\ \text { DB: } & \text { Delinquent behavior } \\ \text { DSM-IV-TR: } & \text { Fourth version revised of the Diagnostic } \\ & \text { and Statistical Manual of Mental Disorders } \\ \text { EP: } & \text { Externalizing problems } \\ \text { FSIQ: } & \text { Full-scale intellectual quotient } \\ \text { IP: } & \text { Internalizing problems } \\ \text { IQ: } & \text { Intellectual quotient } \\ \text { PDD: } & \text { Pervasive developmental disorder } \\ \text { SC: } & \text { Somatic complaints } \\ \text { SP: } & \text { Social problems } \\ \text { SVPD: } & \text { Significant verbal-performance } \\ & \text { discrepancy } \\ \text { TP: } & \text { Thought problems } \\ \text { TS: } & \text { Total score } \\ \text { WI: } & \text { Withdrawn. }\end{array}$




\section{Conflict of Interests}

The authors declare that they have no conflict of interests.

\section{Acknowledgments}

This research has been supported by a Grant from the "Hospices Civils de Lyon" (AO HCL 2004-UF 31245). The authors thank Pr. Eric Fombonne, Pr. Frank Verhulst, and Dr. Jan van der Ende for answering questions and Mr. Mathieu Grivès, archivist at the Department of Child and Adolescent Psychiatry of the Caen University Hospital, for documentary search. They also thank the anonymous reviewers, whose comments helped improve the paper, and finally they thank the children who participated to the study and their parents.

\section{References}

[1] T. M. Newman, "Assessment of giftedness in school-aged children using measures of intelligence or cognitive abilities," in Handbook of Giftedness in Children, D. I. Pfeiffer, Ed., pp. 161176, Springer, New York, NY, USA, 2008.

[2] L. T. Martin, R. M. Burns, and M. Schonlau, "Mental disorders among gifted and nongifted youth: a selected review of the epidemiologic literature," Gifted Child Quarterly, vol. 54, no. 1, pp. 31-41, 2010.

[3] L. Roux-Dufort, "A propos des surdoués," Psychiatrie de l'Enfant, vol. 21, pp. 26-149, 1982.

[4] H. Barchmann and W. Kinze, "Behaviour and achievement disorders in children with high intelligence," Acta Paedopsychiatrica, vol. 53, no. 2, pp. 168-172, 1990.

[5] S. M. Reis and D. B. McCoach, "The underachievement of gifted students: what do we know and where do we go?" Gifted Child Quarterly, vol. 44, no. 3, pp. 152-170, 2000.

[6] M. Liratni and R. Pry, "Enfants à haut potentiel intellectuel: psychopathologie, socialisation et comportements adaptatifs," Neuropsychiatrie de l'Enfance et de l'Adolescence, vol. 59, pp. 327335, 2011.

[7] J. H. Guignard, A. Y. Jacquet, and T. I. Lubart, "Perfectionism and anxiety: a paradox in intellectual giftedness?" PLoS ONE, vol. 7, Article ID e41043, 2012.

[8] L. K. Silverman, "The moral sensitivity of gifted children and the evolution of society," Roeper Review, vol. 17, pp. 110-115, 1994.

[9] J. Peterson, N. Duncan, and K. Canady, "A longitudinal study of negative life events, stress, and school experiences of gifted youth," Gifted Child Quarterly, vol. 53, no. 1, pp. 34-49, 2009.

[10] P. M. Janos, H. C. Fung, and N. M. Robinson, "Self-concept, self-esteem, and peer relations among gifted children who feel 'different,' Gifted Child Quarterly, vol. 29, pp. 78-82, 1985.

[11] C. Zahn-Waxler, B. Klimes-Dougan, and M. J. Slattery, "Internalizing problems of childhood and adolescence: prospects, pitfalls, and progress in understanding the development of anxiety and depression," Development and Psychopathology, vol. 12, no. 3, pp. 443-466, 2000.

[12] J. J. Hudziak, T. M. Achenbach, R. R. Althoff, and D. S. Pine, "A dimensional approach to development psychopathology," International Journal of Methods in Psychiatric Research, vol. 16, no. 1, pp. S16-S23, 2007.

[13] S. E. Shaywitz, J. M. Holahan, J. M. Fletcher, D. A. Freudenheim, R. W. Makuch, and B. A. Shaywitz, "Heterogeneity within the gifted: higher IQ boys exhibit behaviors resembling boys with learning disabilities," Gifted Child Quarterly, vol. 45, no. 1, pp. 16-23, 2001.

[14] I. N. Grossberg and D. G. Cornell, "Relationship between personality adjustment and high intelligence: terman versus Hollingworth," Exceptional children, vol. 55, no. 3, pp. 266-272, 1988.

[15] B. S. Burks, D. W. Jensen, and L. M. Terman, The Promise of Youth: Follow-Up Studies of a Thousand Gifted Children, vol. 3, Stanford University Press, Stanford, Calif, USA, 1930.

[16] L. S. Hollingworth, Gifted Children: Their Nature and Nurture, MacMillan, New York, NY, USA, 1926.

[17] L. S. Hollingworth, Children above 180 IQ: Their Origins and Development, Yonkers on Hudson: World Book, 1942.

[18] W. D. Lewis, "Some characteristics of very superior children," Journal of Genetic Psychology, vol. 62, pp. 301-309, 1943.

[19] L. K. Silverman, "The construct of asynchronous development," Peabody Journal of Education, vol. 72, pp. 36-58, 1997.

[20] G. Alsop, "Asynchrony: intuitively valid and theoretically reliable," Roeper Review, vol. 25, pp. 118-127, 2003.

[21] L. Vaivre-Douret, "Developmental and cognitive characteristics of "high-level potentialities" (highly gifted) children," International Journal of Pediatrics, vol. 2011, Article ID 420297, 14 pages, 2011.

[22] D. Wechsler, Echelle d'intelligence de Wechsler pour enfants, troisième édition (WISC-III), Les Editions du Centre de Psychologie Appliquée, Paris, France, 1996.

[23] R. A. Berk, "Verbal-performance IQ discrepancy score: a comment on reliability, abnormality, and validity," Journal of Clinical Psychology, vol. 38, no. 3, pp. 638-641, 1982.

[24] J. D. Sweetland, J. M. Reina, and A. F. Tatti, "WISC-III verbal/ performance discrepancies among a sample of gifted children," Gifted Child Quarterly, vol. 50, no. 1, pp. 7-10, 2006.

[25] A. Bessou, C. Montlahuc, J. Louis et al., "Profil psychométrique de 245 enfants intellectuellement précoces au WISC-III," Approche Neuropsychologique des Apprentissages chez l'Enfant, vol. 81, pp. 23-28, 2005.

[26] L. Vaivre-Douret, "Les caractéristiques développementales d'un échantillon d'enfants tout venant à "hautes potentialities" (surdoués)," Neuropsychiatrie de l'Enfance et de l'Adolescence, vol. 52, pp. 129-141, 2004.

[27] American Psychiatric Association, Diagnostic and Statistical Manual of Mental Disorders, Fourth Version Revised, American Psychiatric Association, Washington, DC, USA, 2000.

[28] T. M. Achenbach, Manual for the Child Behavior Checklist/4-18, University of Vermont, Department of Psychiatry, Burlington, Vt, USA, 1991.

[29] E. Fombonne, A. M. Chendan, S. Carradec et al., "Le Child Behaviour Checklist: un instrument pour la recherche en psychiatrie de l'enfant," Psychiatry \& Psychobiology, vol. 3, pp. 409-418, 1988.

[30] E. Fombonne, "The Child Behaviour Checklist and the Rutter Parental Questionnaire: a comparison between two screening instruments," Psychological Medicine, vol. 19, no. 3, pp. 777-785, 1989.

[31] E. Fombonne, "The use of questionnaires in child psychiatric research: measuring their performance and choosing an optimal cut-off," Journal of Child Psychology and Psychiatry and Allied Disciplines, vol. 32, no. 4, pp. 677-693, 1991.

[32] E. Fombonne, "Parent reports on behaviour and competencies among 6-11-year-old French Children," European Child \& Adolescent Psychiatry, vol. 1, no. 4, pp. 233-243, 1992. 
[33] M. Y. Imanova, T. M. Achenbach, L. Dumenci et al., “Testing the 8-syndrome structure of the Child Behavior Checklist in 30 societies," Journal of Clinical Child \& Adolescent Psychology, vol. 36, pp. 405-417, 2007.

[34] H. R. Bird, G. Canino, and M. S. Gould, "Use of the Child Behavior Checklist as a screening instrument for epidemiological research in child psychiatry: results of a pilot study," Journal of the American Academy of Child and Adolescent Psychiatry, vol. 26, no. 2, pp. 207-213, 1987.

[35] T. M. Achenbach and D. M. Ndetei, "Clinical models for child and adolescent behavioral, emotional, and social problems," in IACAPAP E-Textbook of Child and Adolescent Mental Health, J. M. Rey, Ed., Chapter A.3, International Association for Child and Adolescent Psychiatry and Allied Professions, Geneva, Switzerland, 2012.

[36] D. Coghill and E. J. S. Sonuga-Barke, "Categories versus dimensions in the classification and conceptualisation of child and adolescent mental disorders-implications of recent empirical study," Journal of Child Psychology and Psychiatry and Allied Disciplines, vol. 53, no. 5, pp. 469-489, 2012.

[37] M. Rutter, "Research review: child psychiatric diagnosis and classification: concepts, findings, challenges and potential," Journal of Child Psychology and Psychiatry and Allied Disciplines, vol. 52, no. 6, pp. 647-660, 2011.

[38] A. Stringaris, "Irritability in children and adolescents: a challenge for DSM-5," European Child and Adolescent Psychiatry, vol. 20, no. 2, pp. 61-66, 2011.

[39] R. R. Althoff, "Dysregulated children reconsidered," Journal of the American Academy of Child and Adolescent Psychiatry, vol. 49, no. 4, pp. 302-305, 2010.

[40] S. H. McConaughy, T. M. Achenbach, and C. L. Gent, "Multiaxial empirically based assessment: parent, teacher, observational, cognitive, and personality correlates of child behavior profile types for 6- to 11-year-old boys," Journal of Abnormal Child Psychology, vol. 16, no. 5, pp. 485-509, 1988.

[41] A. Sourander, P. Jensen, M. Davies et al., "Who is at greatest risk of adverse long-term outcomes? The Finnish from a boy to a man study," Journal of the American Academy of Child and Adolescent Psychiatry, vol. 46, no. 9, pp. 1148-1161, 2007.

[42] H. M. Koot and F. C. Verhulst, "Prediction of children's referral to mental health and special education services from earlier adjustment," Journal of Child Psychology and Psychiatry and Allied Disciplines, vol. 33, no. 4, pp. 717-729, 1992.

[43] F. R. Volkmar, R. Paul, A. Klin, and D. J. Cohen, Handbook of Autism and Pervasive Developmental Disorders, John Wiley \& Sons, Hoboken, NJ, USA, 2005.

[44] M. Neihart, "Gifted children with asperger's syndrome," Gifted Child Quarterly, vol. 44, no. 4, pp. 222-230, 2000.

[45] M. Foley Nicpon, A. F. Doobay, and S. G. Assouline, "Parent, teacher, and self perceptions of psychosocial functioning in intellectually gifted children and adolescents with autism spectrum disorder," Journal of Autism and Developmental Disorders, vol. 40, no. 8, pp. 1028-1038, 2010.

[46] S. G. Assouline, M. Foley Nicpon, and L. Dockery, "Predicting the academic achievement of gifted students with autism spectrum disorder," Journal of Autism and Developmental Disorders, vol. 42, pp. 1781-1789, 2012.

[47] F. Happé and A. Ronald, "The "fractionable autism triad": a review of evidence from behavioural, genetic, cognitive and neural research," Neuropsychology Review, vol. 18, no. 4, pp. 287304, 2008.
[48] C. J. Sowa and K. M. May, "Expanding Lazarus and Folkman's paradigm to the social and emotional adjustment of gifted children and adolescents (SEAM)," Gifted Child Quarterly, vol. 41, no. 2, pp. 36-43, 1997.

[49] F. Guénolé, J. Louis, C. Creveuil et al., "Etude de l’anxiété trait dans un groupe de 111 enfants intellectuellement surdoués," L'Encéphale, 2013.

[50] M. J. Sandstrom and P. Cramer, "Defense mechanisms and psychological adjustment in childhood," Journal of Nervous and Mental Disease, vol. 191, no. 8, pp. 487-495, 2003.

[51] J. S. Renzulli, "The three-ring conception of giftedness: a developmental model of creative productivity," in Conceptions of Giftedness, R. J. Sternberg and J. E. Davidson, Eds., pp. 53-92, Cambridge University Press, New York, NY, USA, 1986.

[52] S. M. Reis and T. P. Hébert, "Gender and giftedness," in Handbook of Giftedness in Children, D. I. Pfeiffer, Ed., pp. 271292, Springer, New York, NY, USA, 2008.

[53] M. Bot, B. J. E. De Leeuw Den Bouter, and M. C. Adriaanse, "Prevalence of psychosocial problems in Dutch children aged 812 years and its association with risk factors and quality of life," Epidemiology and Psychiatric Sciences, vol. 20, no. 4, pp. 357365, 2011.

[54] R. A. Bornstein and J. D. Matarazzo, "Wechsler VIQ versus PIQ differences in cerebral dysfunction: a literature review with emphasis on sex differences," Journal of Clinical Neuropsychology, vol. 4, no. 4, pp. 319-334, 1982.

[55] S. Sugarman, Piaget's Construction of the Child's Reality, Cambridge University Press, New York, NY, USA, 1987.

[56] B. Gibello, "Pathological cognitive disharmony and reasoning homogeneity index," Journal of Adolescence, vol. 6, no. 2, pp. 109-130, 1983. 


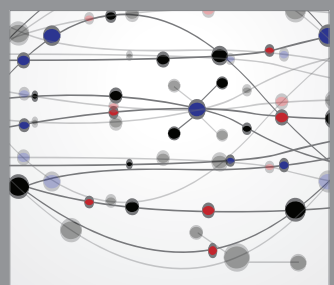

The Scientific World Journal
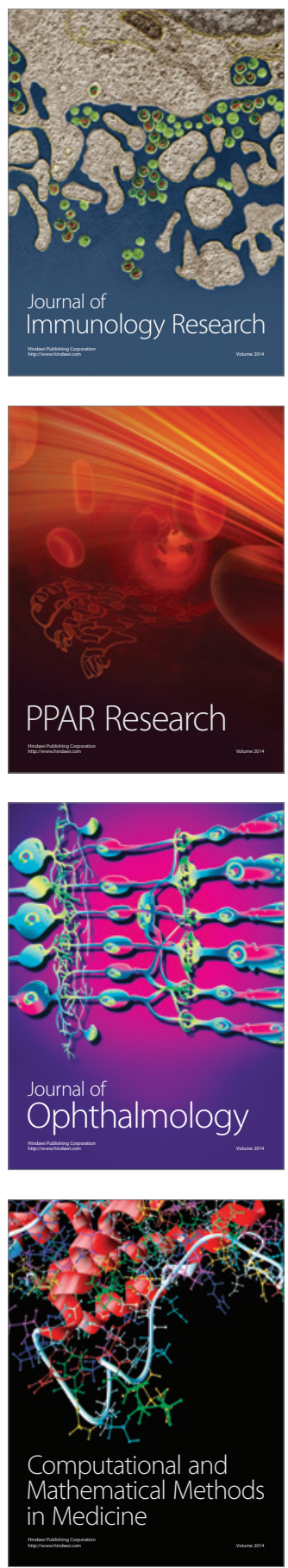

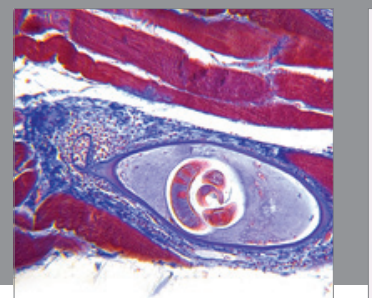

Gastroenterology

Research and Practice
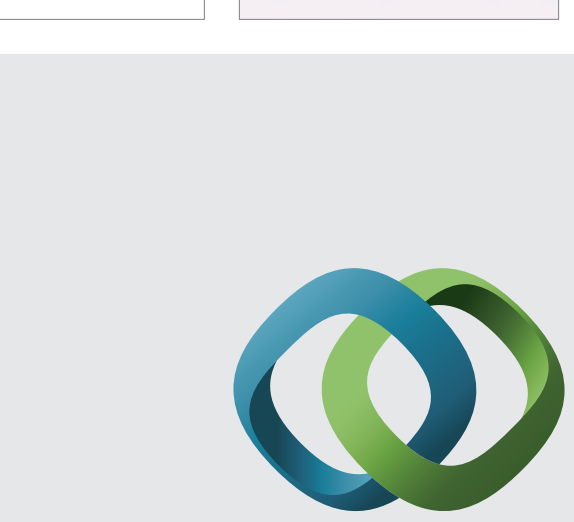

\section{Hindawi}

Submit your manuscripts at

http://www.hindawi.com
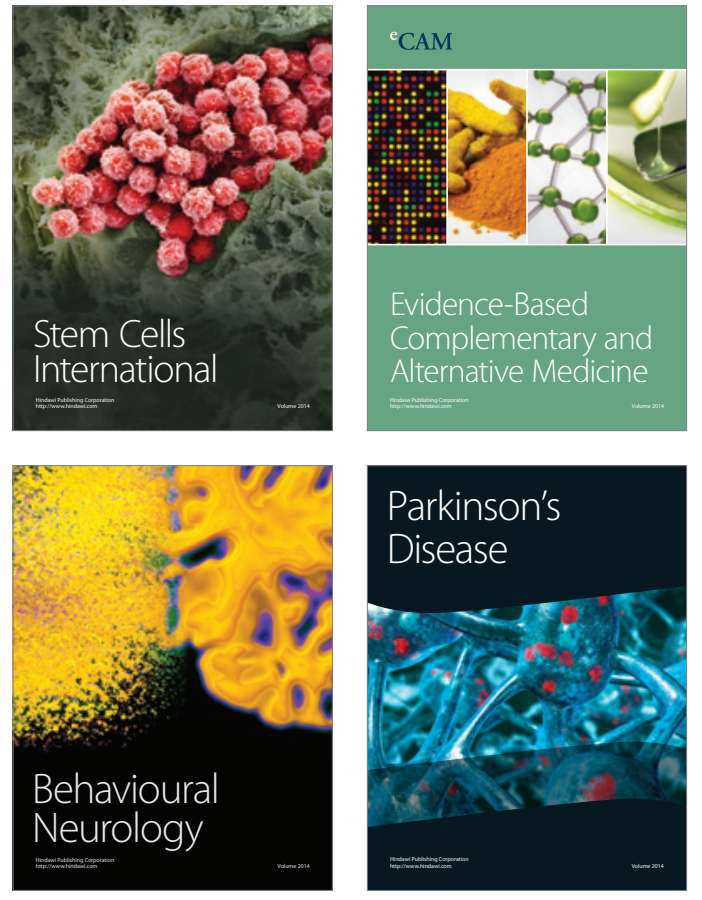
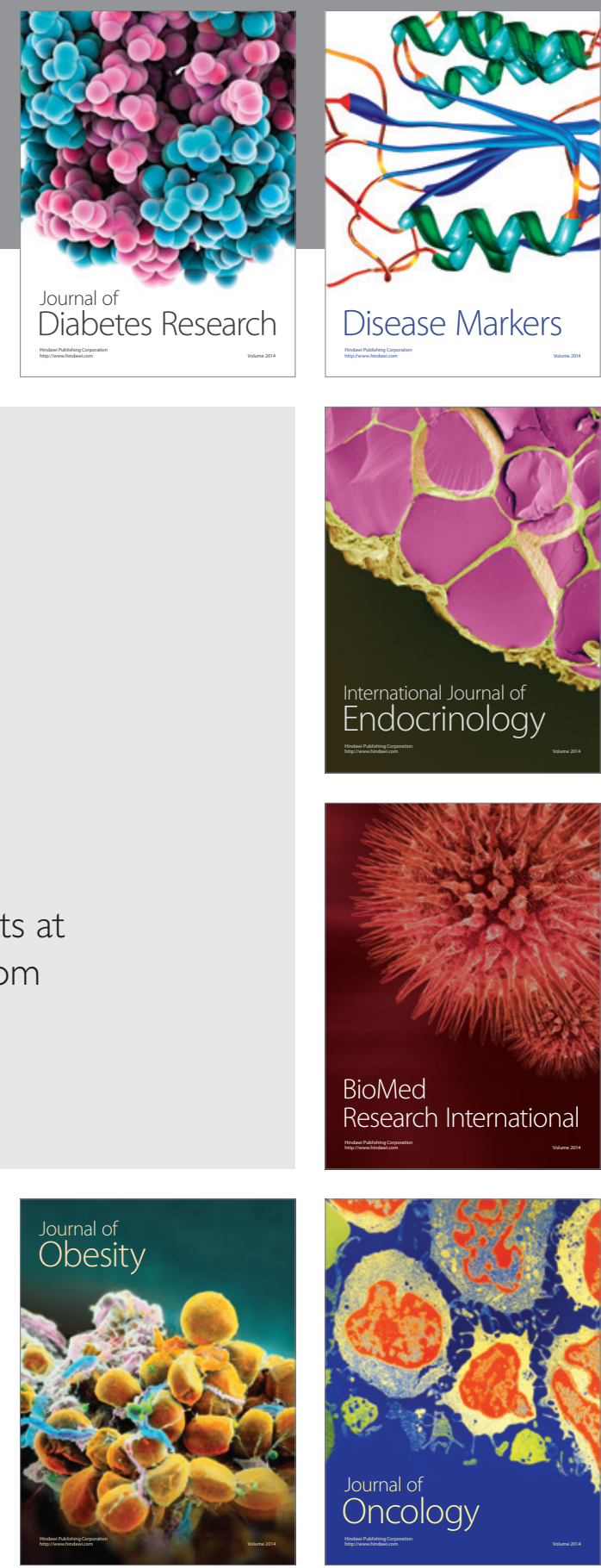

Disease Markers
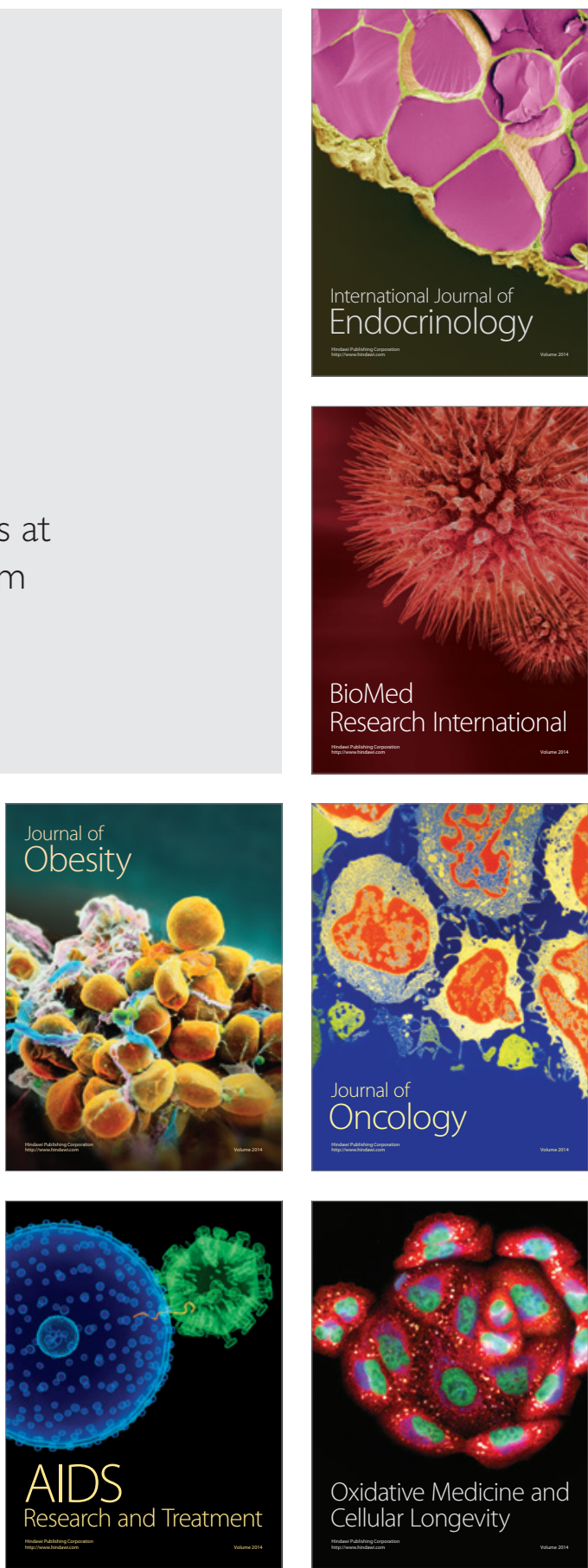